\title{
Scale Development Measuring Young Adults Attitudes Toward Electricity Saving Behaviour: An Indonesia Context
}

\author{
Indah Fatmawati \\ \{indahfatmawati@umy.ac.id\} \\ Universitas Muhammadiyah Yogyakarta, Indonesia,
}

\begin{abstract}
This study describes the development of instruments measuring young adults' attitude toward electricity saving behaviour. Based on principles of scale purification, this study is started with qualitative preliminary study to confirm the opinion that public awareness to save electricity energy is still low and young adults are one of the age groups who most unaware to electricity saving behaviour. The study then followed by scale purification steps, involved 126 respondents for initial step and 254 respondents for the main step. Scale purification steps included: determine the domain of attitude toward electricity saving behaviour, identification of underlying dimensions of attitude toward electricity saving behaviour, generating the indicators, initial test of the indicators to limited respondents, test the coefficient of alpha and performing factor analysis, revise the instruments, assign the revised instruments to larger respondents, performing scale purification and establishing the final instruments. Results showed that the attitude toward electricity saving behaviour was determined by 1) belief, 2) perceived scarcity, 3) perceived risk, 4) reluctant and 5) evaluation. This study also develops indicators to measure intention toward electricity saving behaviour.
\end{abstract}

Keywords: belief, perceived scarcity, perceived risk, reluctant, evaluation, attitude and intention.

\section{Introduction}

The increasing in energy demand nowadays showing an unsustainable trend and the necessary actions are needed to guarantee the sustainability of energy availability in the earth. Attitude and behaviour toward energy saving is an important issue in developing countries which have limitations in energy supply such as Indonesia. Preliminary studies prior to this research showed that awareness to perform electricity saving behaviour is very low among young adults. Persuasive efforts are needed to encourage them to use energy efficiently.

Freiden and Downs (1986) explained that overcoming the energy problem can be conducted at least from three sides: 1) technological advantage, e.g. create synthetic fuels, 2) government intervention, e.g. by determining the speed limit of vehicles, and 3) encourage people to make changes to save energy in their daily life (Freiden and Downs, 1986). Support for energy conservation programs through communication programs that encourage people to save energy is needed. However, electricity energy saving behaviour can be specific for every country. Based on literature review prior to this study, it is not easy to find a standardized measurement to measure energy saving behaviour, especially in Indonesia. This study tried to develop some instruments that specifically measure attitude toward electricity energy saving behaviour which considering uniqueness of attitude toward electricity energy saving behaviour in Indonesia. The process of instrument development was performed referred to the 
principles of scale purification (Churchill, 1979). This is a pilot study to develop a scale measuring energy saving behaviour for the next research step.

\section{Literarature Review: Domain Of Attitude Toward Electricity Energy Saving}

According to review of some previous research, it is known that research in energy conservation behavior have been conducted (both in macro and micro perspectives (Hori et al., 2013). Many previous researchs have been conducted in energy conservation behaviour to explain factors underlying motives to perform energy saving behaviour. Guerin et al., 2000 investigated occupant predictors of household energy behaviour and consumption, based on a theoretical model developed in their prior research (Guerin, Becky and Julie, 2000) called human ecosystem theory (Guerin et al., 2000). This model showed the relationship between household (human organism), natural environment, social environment and the designed environment in energy consumption.

Human ecosystem theory explained that changing in energy consumption behaviour could be predicted from occupant predictors. Occupant predictor is including: occupant characteristics (age, income, home ownership, education, number of occupants, physical size of house, daily occupancy rate, appliance ownership, and gender), occupant attitude (comfort, health concern, motivation, source credibility) and occupant actions (major weatherization, response to incentives, participation in energy audit). These findings showed that attitude is one of important predictors of energy conservation behaviour and energy consumption change.

In energy conservation context, attitude has been defined as both unidimensional and multidimensional constructs. Hutton (1982) defined attitude as an unidimensional overall feeling toward an object and its function (Hutton, 1982). Awad, Johnston, Feldman and Williams (1983) using variety measurements (31 statements) and found four factors that account for attitude construct including: cynicism, concern for supply, avowal of social norms and home economics (Awad et al., 1983). Semenik, Belk and Painter (1982) explained that income, education, occupation, age, family life cycle and gender are factors that influencing attitude and behaviour toward energy conservation (Semenik et al., 1982).

Conceptually, attitude defined as an individuals' general evaluation made to himself, other people, objects or specific issues (Petty and Cacioppo, 1986). This study defined attitude as a summary of individuals' evaluation of electricity energy saving messages s/he receives. Operationally, attitude is defined as attitudes toward electricity energy-saving behaviour. Measurement of attitudes toward electricity energy saving behaviour is developed based on the theory of attitude components which states that the attitude component consist of cognitive, affective and behavioural.

The relationship between attitude and behaviour toward energy conservation was also mixed. Awad et al., (1983) concluded that: 1) attitude is predictive for behavioural intention, 2) beliefs about the consequences of a behaviour are predictive of behavioural intentions and 3) behavioural intention regarding different electricity end users are related to different general attitudes toward conservation (Awad et al., 1983).

Intention is seen as a determinant variable for the actual behaviour (Schiffman et al., 2012). The stronger a person's intention to behave, the greater the success of the prediction of behaviour. (Kamins and Marks (1987) explained, research findings have clearly showed that, knowledge that is activated and available during the evaluation process of a message greatly influence the decisions and consistency of attitudes and behaviour (Kamins and Marks, 1987). 
Some factors affecting the activation and availability of information itself include a message clarity. Intention known as mediating construct on attitude-behaviour relationship. In order to get a complete insight about attitude, this study also testing the instrument of intention.

\section{Methodology}

The purpose of this study is exploratory. Exploratory study is conducted when the researcher does not have sufficient knowledge about the context of the research topic. In order to develop instrument to measure attitude toward electricity saving behaviour, this study is conducted in two steps, ie: preliminary study and main study. The preliminary study is conducted using qualitative method. While the main study is using quantitative method involving two stages data collection.

\subsection{Preliminary Study}

The purpose of preliminary study are: 1) to ensure that the problem of reluctance to perform electricity saving behaviour is really happen, and 2) to determine the proper subject that most do not care to the program of electricity saving behaviour. The goals were achieved in three ways:

1. Interview with the Public Relation Affair Manager of Electricity State Owned Enterprise in Jogjakarta Indonesia (PT. Perusahaan Listrik Negara). The interview lasted for about 120 minutes using structured questions. The purpose of this interview is to confirm whether the low of public awareness to perform electricity energy saving behaviour is really happen. Results of interview revealed that Indonesia is facing the problem of imbalance between the growth of electricity demand and the growth of generator capacities. The government have started the electricity energy saving program since 2002. However, there were no significant effects of the program on energy saving behaviour. Currently, the main purpose of this program is to reduce the load of the peak hours. The government still facing the problem of how to persuade household consumers to get involve with the program. The awareness to perform electricity saving behaviour among industries and households consumers is still low and it means that the problem of electricity crisis is potentially to be happened.

2. Interview to 48 households and most of them are housewife, selected by convenience sampling. The purpose of the interview is to confirm whether the notion that people awareness to perform electricity energy saving behaviour is really happen and to identify which of the consumer segments who do not care to electricity energy saving behaviour program. Each interview lasted about 15 minutes. Results of this phase revealed that: 1) among of 48 informants, $87,5 \%$ admitted that they haven't been perform electricity energy saving behaviour yet, 2) their young adults children is the family member that most do not concern to the electricity energy saving program. Most of the informants revealed that electricity energy saving behaviour bring inconvenience consequences, and they worried to loose of their work motivation when they have to work under inconvenience condition. Moreover, they felt that not performing electricity energy saving is not risky as long as they can pay their electricity bill. These findings confirm the notion of the first interview that people awareness to perform electricity saving behaviour are low.

3 . Focused group discussion. This step involved three groups of undergraduate school of business students. Each group consists of 4-6 students. This focused group discussion revealed that: almost all of the participants admitted that they do not care about energy saving behaviour. Many reasons were revealed for this opinion, such as: they are in their 
growth stage so that they need many facilities to support all of their activities and energy saving action will limit their daily activities, energy saving behaviour is not their business, energy saving behaviour means inconvenience, the lack of energy resources is attributed as the government mistakes in managing national energy resources and some scepticism such as why should they perform energy saving while other people do not, why did not the government give example of energy saving behaviour in daily life, why did not the government asked the industry segment to perform energy saving behaviour, etc.

Based on the results of preliminary study, it is concluded that: 1). People awareness to perform electricity energy saving behaviour is still low, 2) the problem of electricity crisis is potentially to be happen if people do not being encouraged to perform electricity energy saving behaviour and, 3) young adult is one of consumer segment whose least awareness to perform electricity energy saving behaviour.

\subsection{Main Study: The Scale Purification.}

The second step of this study is the main study that consists of two stages exploratory studies. The steps of this phase reflect the steps of scale purification developed by Churchill (1979). Here are the steps that have been conducted:

1. Define the domain of attitude towards electricity saving behaviour construct. Firstly, the concept of attitude is defined and followed by defining the operational definition of attitude toward electricity saving behaviour. Referred to previous relevant literatures, conceptually, attitude is defined as an individual's general evaluation made to himself, other people, objects or specific issues (Petty and Cacioppo, 1986). Operationally, attitudes conceptualized as attitudes toward electricity energy-saving behaviour and defined as a summary of the evaluation of electricity energy saving messages $\mathrm{s} /$ he receives.

2. Based on the operational definition of the construct, some indicators that describe the domain of the construct were developed through literature review and the results of preliminary study and in depth interview results with an electricity expert and two behavioural science experts. The indicators then were edited to ensure that it didn't have double meaning.

3. Develop the attitude dimensions and the indicators based on the results of previous steps and referred to previous research instruments. Some previous research have developed the attitude dimensions in energy conservation (Freiden and Downs, 1986)(Sin et al., 2003). Attitude measurements were developed into several dimensions: 1) belief about energy saving (7 items), 2) the benefits of energy saving (6 items), 3) perceived scarcity (5 items), 4) perceived risk (3 items), 5) reluctance to perform energy saving (item 6), 6) involvement (5 items), and 7) evaluation (10 items). The dimensions of perceived scarcity and perceived risk were added to measure the effect of information of scarcity in energy resources. The dimension of reluctance was also added as the preliminary studies revealed the presence of reluctance to perform electricity energy saving among young adults. This study also investigating the measurement of electricity energy saving intention using 9 items.

4. Test the early instrument to limited respondents. The first step instruments consist of 42 items for attitude and 9 items for intention and were tested to 126 respondents of school of business students in Jogjakarta. The internal consistencies then were measured and a factor analysis to determine its dimensions was performed. This testing also tested 7 items of intention to perform electricity saving behaviour.

5. Evaluate the findings of the prior step to improve the format of the questions. Results of factor analysis, after three iterations, did not give the expected results. From 42 items, only 
17 items that have loading factor more than 0.4 and they're not grouping into dimensions as expected.

6. Based on factor analysis results, some improvements were made by changing the form of indicators from formative into reflective form, dropping some of the items that considered unnecessary and added some needed items. This step also dropped the dimension of engagement. This step results 42 indicators that will be tested in the next step including intention indicators.

7. Repeat the testing using the revised questionnaire. The respondents were 254 students of school of business of a state university in Yogyakarta.

8. Analyse the data using factor analysis and reliability test then drawing conclusions. Data analysis was performed using SPSS. Basically, the steps of data analysis were a model measurement. These analysis included validity and reliability tests.

Validity means true or correct and it indicates the degree to which a construct is able to generalize the findings beyond the study. Validity also shows the quality of the measurement (Neuman, 2013). Validity refers to how well the conceptual and operational definition match each other. Validity was tested using exploratory factor analysis. Validity tests that were performed in this study included: 1) face validity test, 2) content validity test and 3) construct validity test.

Face validity is an assessment conducted by scientific community to ensure that the indicators really measure the construct. Content validity related to the question whether the full content of the definition of a variable represented in the measure. Measurement of the content validity involves three steps: 1) specify the content in a construct definition, 2) identify examples from all areas of definition and 3) develop indicators that include all of parts of the definition (Neuman, 2013). Requirements for these testing were met by the phase of discussion with the experts in energy conservation and behavioural research.

Construct validity indicates the extent to which a researcher can generalize the findings beyond the study. It also shows the quality of measurement (Neuman, 2013). Construct validity are categorized into two types, namely convergent validity and discriminant validity. Convergent validity means that multiple measures of the same constructs hang together or operate in similar ways. It indicates the validity of an instrument that is determined based on its convergence with other similar instruments that measure the construct. This is shown by the high value of the correlation between indicators that measure the same concept. Convergent validity indicated from rotated factor loading matrix component that relatively large at around 0.7 (Hair, Anderson, Tatham and Black 2013). Discriminant validity also called divergent validity. It indicates the validity of an instrument that is determined based on the low correlation with other instruments that are used to measure different constructs. Discriminant validity viewed from a relatively small loading factor (loading factor of a construct with the indicator must be greater than the loading factor of the indicator with other constructs).

Reliability means dependability or consistency. It showed stability in instrument measurement. An instrument said to be reliable if it can deliver the same results when used to repeat measuring the same objects (Neuman, 2013). Reliability testing aims to confirm that the indicators used are quite represent the constructs of the study. Reliability is indicated by the value of Cronbach Alpha at 0,7 (Hair et al., 2013). Reliability tests can also be performed by calculating corrected item to total correlation. The minimum criteria is 0.5 . 


\section{Findings}

Results of Validity Tests This section explains the results of the final step of scale purification using factor analysis. Testing of attitude and intention constructs was performed using principal axis factor analysis with varimax rotation to assess the underlying structure of the 35 items of attitude construct and 7 items of intention construct. The number of factors was determined as 6 factors.

The results of factor analysis in the second stage showed the KMO value of 0.806 or greater than 0.7 (Nancy et al., 2005). This value indicated an adequate number of items for each factor. These results also indicated that the correlation matrix is adequate to be extracted and the significance value of correlation for factor analysis is 0.000 . The significance value indicates that the correlation matrix is significantly different from the identity matrix when all of the correlations between variables are zero.

Results of factor analysis in the second stage showed better loading factors. The results of factor analysis after 3 iterations are presented in Table 1. From the 42 attitude indicators and 9 intention indicators were tested, there are 32 indicators which have factor loading greater than 0.4 and grouped into six factors as expected. The attitude construct in the second phase of testing using 254 respondents is categorized into five dimensions, i.e.: 1) belief (6 items), 2) perceived scarcity (3 items), 3) perceived risk (4 items), 4) reluctant (3 items) and 5) evaluation ( 9 items). While the intention construct is categorized into one factor consists of 7 items.

Construct validity was measured from convergent and discriminant validity. Convergent validity measures the degree of convergence between the indicators (Neuman, 2013). It was performed using iteration convergence varimax factor analysis. The test results showed that all indicators met the criteria of factor loading $>0.4$. Discriminant validity testing was performed to test whether two or more constructs being tested are different and each is an independent construct. Results as shown in Table 1 revealed that attitude and intention constructs have good discriminant validity.

Table 1. Rotated Component Matrix of Attitude

\begin{tabular}{|c|c|c|c|c|c|c|}
\hline \multirow[t]{2}{*}{ Indicators } & \multicolumn{6}{|c|}{ Components } \\
\hline & 1 & 2 & 3 & 4 & 5 & 6 \\
\hline Belief1 & .438 & & & & & \\
\hline Belief2 & .730 & & & & & \\
\hline Belief3 & .825 & & & & & \\
\hline Belief4 & .751 & & & & & \\
\hline Belief5 & .585 & & & & & \\
\hline Belief6 & .562 & & & & & \\
\hline Scarcity1 & & .779 & & & & \\
\hline Scarcity2 & & .717 & & & & \\
\hline Scarcity3 & & .793 & & & & \\
\hline Risk1 & & & .587 & & & \\
\hline Risk2 & & & .764 & & & \\
\hline Risk3 & & & .765 & & & \\
\hline Risk4 & & & .610 & & & \\
\hline Reluctant1 & & & & .714 & & \\
\hline Reluctant2 & & & & .836 & & \\
\hline Reluctant3 & & & & .770 & & \\
\hline
\end{tabular}




\begin{tabular}{|c|c|c|c|c|c|c|}
\hline \multirow[t]{2}{*}{ Indicators } & \multicolumn{6}{|c|}{ Components } \\
\hline & 1 & 2 & 3 & 4 & 5 & 6 \\
\hline Evaluation2 & & & & & .584 & \\
\hline Evaluatin3 & & & & & .550 & \\
\hline Evaluation4 & & & & & .573 & \\
\hline Evaluation5 & & & & & 489 & \\
\hline Evaluation6 & & & & & 668 & \\
\hline Evaluation8 & & & & & 637 & \\
\hline Evaluation9 & & & & & 603 & \\
\hline $\begin{array}{l}\text { Evaluation1 } \\
0\end{array}$ & & & & & .704 & \\
\hline $\begin{array}{l}\text { Evaluation1 } \\
1\end{array}$ & & & & & 658 & \\
\hline Intention1 & & & & & & .585 \\
\hline Intention2 & & & & & & .587 \\
\hline Intention3 & & & & & & .790 \\
\hline Intention4 & & & & & & .735 \\
\hline Intention5 & & & & & & .738 \\
\hline Intention6 & & & & & & .811 \\
\hline Intention7 & & & & & & .797 \\
\hline
\end{tabular}

Reliability test was performed using SPSS. The indicator of this testing is Cronbach Alpha. Results of reliability test were showed in Table 2

Table 2. Results of Reliability Test

\begin{tabular}{lcc}
\hline Construct & Cronbach's Alpha & Number of items \\
\hline Attitude & .895 & 25 \\
\hline Intention & .897 & 7 \\
\hline \multicolumn{3}{r}{}
\end{tabular}

Results of reliability test showed that all of the constructs are reliable. It was indicated by the magnitude of Cronbach Alpha 0,895 (attitude) and 0,897 (intention). Based on the Cronbach Alpha criteria that require the Cronbach Alpha score of 0,6, those results showed that all of the indicators in each construct have internal consistency.

The final indicators of attitude and intention constructs were presented in Table 3 and Table 4. Table 3 showed that the attitude construct consists of five dimensions with 25 indicators. They are: : 1) belief (6 items), 2) perceived scarcity (3 items), 3 ) perceived risk (4 items), 4) reluctant (3 items) and 5) evaluation (9 items). While from the Table 4 , we can see that the intention construct is categorized into one factor consists of 7 items.

Table 3. Final Dimensions and Indicators

\begin{tabular}{lll}
\hline No & Dimensions & \\
\hline 1. & Belief & 1. Electricity energy saving is needed to save money \\
& & 2. Electricity energy saving is important to avoid rolling blackout \\
& & $\begin{array}{l}\text { 3. Electricity energy saving is important to increase electricity energy supply in rural } \\
\text { areas }\end{array}$ \\
\hline
\end{tabular}




\begin{tabular}{|c|c|c|}
\hline No & Dimensions & Indicators \\
\hline & & $\begin{array}{l}\text { 4. Electricity energy saving is important to increase electricity energy supply for the next } \\
\text { generation } \\
\text { 5. Electricity energy saving will reduce } \mathrm{CO} 2 \text { emission } \\
\text { 6. Electricity energy saving is urgent to perform }\end{array}$ \\
\hline 2. & $\begin{array}{l}\text { Perceived } \\
\text { scarcity }\end{array}$ & $\begin{array}{l}\text { 1. Sources of electricity energy are getting scarce } \\
\text { 2. The frequency of rolling blackouts is increasing } \\
\text { 3. I began to worry about the energy crisis due to scarcity of energy resources }\end{array}$ \\
\hline 3. & $\begin{array}{l}\text { Perceived } \\
\text { risk }\end{array}$ & $\begin{array}{l}\text { 1. Our next generation will face the risk of we do not save electricity energy. } \\
\text { 2. I will have to take the high cost risk of not performing eletricity energy saving } \\
\text { 3. I will have to take the risk of rolling blackout due to not performing eletricity energy } \\
\text { saving } \\
\text { 4. Rural areas will lack of electricity energy supply because of we are wasting electricity } \\
\text { energy }\end{array}$ \\
\hline 4. & Reluctance & $\begin{array}{l}\text { 1. Performing electricity energy saving makes me working harder } \\
\text { 2. Performing electricity energy saving is inconveniences } \\
\text { 3. Performing electricity energy saving sacrificing conveniences }\end{array}$ \\
\hline 5. & Evaluation & $\begin{array}{l}\text { 1. Electricity energy saving program is important. } \\
\text { 2. Electricity energy saving program is effective } \\
\text { 3. Electricity energy saving program is useful } \\
\text { 4. Electricity energy saving program is can be trusted } \\
\text { 5. Electricity energy saving program is educative } \\
\text { 6. Electricity energy saving program is relevant } \\
\text { 7. Electricity energy saving program is wise } \\
\text { 8. Electricity energy saving program is safe to perform } \\
\text { 9. Electricity energy saving program is good }\end{array}$ \\
\hline
\end{tabular}

Table 4: Indicators of Intention to Perform Electricity Energy Saving

\begin{tabular}{ll}
\hline Construct & Indicators \\
\hline Intention & 1. I have to get involve in electricity energy saving \\
& 2. I am willing to remind people around me to perform electricity energy \\
saving & 3. I will change my life style so that I can save electricity energy \\
4. I will spend my time to learn further about how to save electricity \\
energy \\
5. I will tell my electricity energy saving efforts to family and friends \\
6. I will save electricity energy starting from this week \\
7. I plan to save electricity energy starting from this week
\end{tabular}

\section{Conclusions}

Results of validity and reliability tests showed that the model measurement requirements have been met. Five factors are known as determinants of attitude toward electricity energy saving behaviour. They are belief, perceived scarcity, perceived risk, reluctant and evaluation. While intention to perform electricity energy saving were formed of one factor.

This research is a pilot study to develop a standardized instrument to measure attitude and intention toward electricity saving behaviour for the next main research. Results of 
measurement model in this study will be used in the next research to measure attitude and intention toward electricity saving behaviour.

Despite of the purpose of this study, measurement developed in this study can be applied in another energy conservation context study especially in attitude toward electricity energy saving program. This measurement also can be applied in another subject whose same characteristics and behaviour in consuming electricity energy with young adultsas well as in another geographic setting whose same characteristics and behaviour with Indonesian context in consuming electricity energy.

\section{References}

[1] Awad, Z. et al. (1983) 'Customer Attitude and Intentions to Conserve Electricity', Advances in Consumer Research, Vol.10, p. 652-654.

[2] Churchill, G. (1979) 'A Paradigm For Developing Better Measures Of Marketing Constructs', Journal of Marketing Research, 16 (1), pp. 64-73.

[3] Freiden, J. and Downs, P. (1986) 'Testing the social involvement model in an energy conservation context', Journal of the Academy of Marketing Science, 14 (3), pp. 13-20.

[4] Guerin, D., L, B. and Coopet, J. G. (2000) 'Occupant predictors of Household Energy Behaviour and Consumption change as Found in Energy Studies Since 1975', Family and Consumer Sciences Journal, 29, p. 48.

[5] Hair, J. et al. (2013) 'Multivariate Analysis', 5(London: Prentice-Hall).

[6] Hori, S. et al. (2013) 'The determinants of household energy-saving behavior: Survey and comparison in five major Asian cities', Energy Policy. Elsevier, 52, pp. 354-362. doi: 10.1016/j.enpol.2012.09.043.

[7] Hutton, R. (1982) ‘Advertising and The Department of Energy's Campaign for Energy Conservation', Journal of Advertising, 11 (2), pp. 27-39.

[8] Kamins, M. A. and Marks, L. J. (1987) 'The Effect of Framing and Advertising Sequencing on Attitude Consistency and Behavioural Intentions', Advances in Consumer Research, Vol. 14, Paul Anderson and Melanie Wallendorf (eds), Ann Arbor, MI: Association for Consumer Research, pp. 168-172.

[9] Nancy, L., Karen, C. B. and George, A. M. (2005) 'SPSS for Intermediate Statistics: Use and Interpretation', (Mahwah, NJ, USA: Lawrence Erlbaum Associate, Inc).

[10] Neuman, W. (1997) 'Social Research Methods', (Allyn and Bacon: Boston).

[11] Petty, R. E. and Cacioppo, J. T. (1986) 'The Elaboration Likelihood Model Of Persuasion', Advances in Experimental Social Psychology, 19 (1), pp. 123-205.

[12] Schiffman, L. G., Kanuk, L. L. and Avard, H. (2012) Consumer Behaviour. New York: Pearson Financial Times/Prentice Hall.

[13] Semenik et al. (1982) 'A Study of Factors Influencing Energy Conservation Behaviour', Advances in Consumer Research, 09, pp. 306-312.

[14] Sin, L., Tse, A. and So, S. (2003) 'Energy conservation behaviour: A consumer survey: Date accessed April, 1, 2008.', (Hong Kong: Department of Marketing at The Chinese University of Hong Kong). 